\title{
Assessment of Fungal Infection of Peritoneal Fluid in Cirrhotic Ascites
}

\author{
Adel Awwad ${ }^{1}$, Mohammed El Shewi ${ }^{1}$, Mohammed Tareif ${ }^{2}$, Adham Mostafa ${ }^{3}$ \\ ${ }^{1}$ Hepatology, Gastroenterology and Infectious Diseases Department, Faculty of Medicine, Benha \\ University, Egypt. \\ ${ }^{2}$ Clinical Pathology Department, Faculty of Medicine,Ain Shams University, Egypt. \\ ${ }^{3}$ Hepatology and Gastroenterology Unit, Al Haram Hospital, Ministry of Health ,Egypt.
}

Corresponding Author Mohammed El Shewi

Mobile:002012245468 59

E mail: mo.elshewi@yahoo.co $m$

Key words: fungal infection, spontaneous fungal peritonitis
Background and study aim: Spontaneous peritonitis (SP) is the most important infectious complication of cirrhotic patients. The aim of this study is to evaluate the occurrence of fungal infection of peritoneal fluid in cirrhotic patients with ascites.

Patients and Methods: Between September 2016 and April 2017, 50 Patients were classified into (SP group) and (non SP group) all patients were subjected to history taking, clinical examination, complete blood count, ESR,CRP, liver profile, kidney function tests, serological tests for viral hepatitis markers, abdominal ultrasonography and diagnostic abdominal paracentesis. The ascitic fluid was subjected to the following: microscobic examination, biochemical examination and microbiological cultures (bacterial and fungal).

Results: MELD score was higher in SP group with Mean \pm SD $23.08 \pm 3.85$. Analysis of the results showed that abdominal pain, hepatic encephalopathy

\section{INTRODUCTION}

Spontaneous peritonitis, bacterial (SBP), is a common and life-threatening complication in patients with liver cirrhosis and ascites, with a mortality of 10 to $50 \%$. It should be suspected in patients with ascites who develop fever, abdominal pain, ileus, and worsening hepatic encephalopathy, though $13 \%$ of patients may lack any signs or symptoms of SBP at the time of presentation [1]. The diagnosis is made if the polymorphonuclear cell (PMN) count in the ascites fluid is and melena were the only significant clinical presentations (chief complaint) in patients with SP compared to non SP group (52\%, $40 \%$ and $8 \%$ respectively). As regard risk factors of ascitic fluid infection, $40 \%$ had previous episodes of SP. In SP patients, mean PMN count in ascitic fluid was $675.20 \pm 420.02$ at the time of diagnosis. Ascitic fluid bacterial culture was positive in only $40 \%$ of SP patients. Ascitic fluid fungal culture was positive in only 2 patient $(8 \%)$ of SP group and negative in all patients of non SP group. The isolated organism was Candida albicans. These 2 patient had proven spontaneous fungal peritonitis owing to the presence of Candida albicans as evidenced by clinical picture of spontaneous peritonitis, high ascitic fluid PMN count and.

Conclusion: Spontaneous fungal peritonitis is less common than SBP but usually presented as a severe disease, so, clinical prediction and early detection helps in proper treatment and better prognosis.

$\geq 250$ cells $/ \mathrm{mm} 3$, culture results are positive and secondary causes of peritonitis are excluded [2].

The impact of fungal infections may be underestimated in clinical routine since the rate of sepsis was higher in patients with fungascites than in those with bacterascites [3].

The aim of this work is to evaluate the occurrence of fungal infection of peritoneal fluid in cirrhotic patients with ascites. 


\section{PATIENTS AND METHODS}

This study was conducted on 50 patients with decompensated chronic liver diseases, child B and $\mathrm{C}$ cirrhosis with ascites admitted to AlShabrawishi hospital

\section{Patients were classified into two groups:}

- Group I: the first 25 consecutive patients with ascitic fluid polymorphonuclear leucocyte (PMN) count $\geq 250 \mathrm{cell} / \mathrm{mm}^{3}$.

- Group II: Included the first 25 consecutive patients with ascitic fluid polymorphnuclear leucocyte (PMN) count $<250$ cell $/ \mathrm{mm}^{3}$.

\section{All patients were subjected to the following:}

I- history taking with particular attention to: Manifestations suggesting SP and history of previous attack of SBP, refractory ascites and drug history.

\section{II- Full general and local examination:}

Looking for signs of liver disease such as palmar erythema, spider naevi, liver size, spleen size, presence of ascites, jaundice and encephalopathy. Signs of SP such as fever, hypotension, tachycardia and abdominal pain.

\section{III- Laboratory investigations:}

1- Complete blood picture, CRP and ESR.

2- Renal function test.

3- Liver profile :

4- Serological tests for viral markers:

- HBsAg

- $\mathrm{HCV} \mathrm{Ab}$

By using enzyme-linked immunosorbent assay technique (ELISA).

\section{IV- Abdominal ultrasonography.}

\section{V- Diagnostic abdominal paracentesis:}

Thirty $\mathrm{ml}$ of the ascitic fluid were aspirated from each patient. The technique of paracentesis was explained to the patient and it was done under aseptic precautions using a wide bore needle. The needle was introduced in the right lower quadrant while the patient lies in supine position. " $Z$ Tracking" technique was used to avoid post paracentesis leaks [4].

This technique is accomplished by displacing (with one gloved hand) the skin approximately 2 $\mathrm{cm}$ downward and then slowly inserting the paracentesis needle mounted on the syringe held in the other hand. The skin is not released until the needle has penetrated the peritoneum and fluid flows. They were subjected to the following:

(A) Physical examination:

$$
\text { - Color. - Aspect. }
$$

(B) Biochemical tests including:

- Total protein content (Human).

- LDH (Human)

- Glucose (Spin react)

(C) Total and differential WBCs counting.

(D) Direct microscopic examination:

Ascitic fluid was examined by direct microscopic examination for the presence of Candida Pseudohyphae or Hyphae, as well as for the presence of Aspergillus hyphae. Ascitic Smear was stained by Gram stain to demonstrate Candida species well. A drop of ascitic centrifugal sediment was added to the India ink on a slide, mixed to demonstrate Cryptococcus neoformans capsules.

(E) Microbiological cultures:

1- Cultures were done to detect any infecting organisms. Culture on MacConkey, blood and Sabouraud's dextrose agar plates without primary enrichment by direct culture method.

2- Ascitic fluid inoculation in 3 vials (Aerobic, Anaerobic and Mycosis Media bottles) of BACTEC 9050 blood culture system

Identification of bacterial organisms:

Microbact (oxoid): gram -negative identification system is used for identification of aerobic and facultatively anaerobic gram negative bacteria (12A for enterobacteriaceae and miscellaneous gram negative bacilli (MGNB).

Identification of fungal organisms:

I- Colony Morphology on Sabouraud's Dextrose agar and Microscopic examination:

Candida species:

The Colonies are whitish or creamy in color, smooth and glistening. Candida also can be grown on blood agar. Diagnosis depends on isolation of the fungus in culture with demonstration of characteristic budding yeasts, hyphae or pseudohyphae with branching and constriction at the septa and production of blastospores near the septa. A partial exception of this rule is Candida glabrata which doesn't produce hyphae or pseudohyphae.

\section{II- Identification of Candida species:}

Colonies grown on Sabouraud's dextrose agar were stained with Gram stain and microscopically examined. Yeast colonies were subjected to: CHROM agar medium: subculture on CHROM agar medium at $\mathrm{c} 37^{\circ} \mathrm{C}$ and examined after 24-48 hours, then colony color was examined and different species of yeast were identified according to the range of color. 
Table (1): Range of colony colors on CHROM agar Candida medium

\begin{tabular}{|l|l|}
\hline Yeast Species & Range of colony colours \\
\hline C. albicans & Green colonies \\
\hline C. glabrata & Dark pink colonies \\
\hline C. Krusi & Pale pink, purple (large rough, spreading colonies with pale edges) \\
\hline C. parapsilosis & White pale pink \\
\hline C. tropicalis & Dark blue to blue gray with purple halo surrounding the colonies in agar \\
\hline
\end{tabular}

Germ tube test: to differentiate between Candida albicans (positive) and non-albicans species (negative).

The data collected were tabulated \&analyzed by SPSS statistical package version 12 IBM compatible computer.

\section{RESULTS}

The results of this study were tabulated and statistically analyzed in tables and figures.

Table (2): Comparison between non SP and SP group regarding complaint

\begin{tabular}{|l|c|c|c|c|}
\hline \multirow{2}{*}{ Complaint } & Non SP & SP & \multicolumn{2}{c|}{ Chi-square test } \\
\cline { 2 - 3 } & No.=25 & No.=25 & $\mathbf{X}^{2} / \mathbf{t}^{*}$ & P-value \\
\hline Abdominal pain & $1(4.0 \%)$ & $13(52.0 \%)$ & & \\
DCL & $21(84.0 \%)$ & $10(40.0 \%)$ & \multirow{2}{*}{19.189} & 0.000 \\
\hline Dyspnea & $3(12.0 \%)$ & $0(0.0 \%)$ & & \\
\hline Melena & $0(0.0 \%)$ & $2(8.0 \%)$ & & \\
\hline
\end{tabular}

Dcl: Disturbed Conscious Level

This table shows that: There was highly statistically significant difference found between non SP group and SP group regarding complaint as $52 \%$ of SP group had abdominal pain.

Table (3): Comparison between non SP and SP group regarding 3 months survival rate.

\begin{tabular}{|l|l|l|l|l|l|l|l|}
\hline \multicolumn{2}{|c|}{ Survival rate } & \multicolumn{2}{c|}{ Non SBP } & \multicolumn{2}{c|}{ SBP } & \multicolumn{2}{c|}{ Chi-square test } \\
\cline { 2 - 8 } & No. & $\%$ & No. & $\%$ & $\mathbf{X}^{\mathbf{2}}$ & P-value \\
\hline \multirow{2}{*}{3 month } & No & 3 & $12.0 \%$ & 14 & $56.0 \%$ & \multirow{2}{*}{10.784} & \multirow{2}{*}{0.001} \\
\cline { 2 - 8 } & Yes & 22 & $88.0 \%$ & 11 & $44.0 \%$ & & \\
\hline
\end{tabular}

This table shows: There was highly statistically significant difference between the two studied group regarding survival rate. 
Table (4): Comparison between non SP and SP group regarding ascitic fluid analysis and culture.

\begin{tabular}{|c|c|c|c|c|c|}
\hline \multirow{2}{*}{\multicolumn{2}{|c|}{ Ascitic fluid }} & \multirow{3}{*}{$\begin{array}{l}\text { Non SP } \\
\text { No.=25 } \\
0(0.0 \%)\end{array}$} & \multirow{2}{*}{$\begin{array}{c}\text { SP } \\
\text { No. }=25\end{array}$} & \multicolumn{2}{|c|}{ Chi-square test } \\
\hline & & & & $\mathbf{t} / \mathbf{X}^{2 *}$ & P-value \\
\hline \multirow{2}{*}{ Color } & Reddish & & $3(12.0 \%)$ & \multirow{2}{*}{$3.191 *$} & \multirow{2}{*}{0.074} \\
\hline & Yellow & $25(100.0 \%)$ & $22(88.0 \%)$ & & \\
\hline \multirow{2}{*}{ Aspect } & Clear & $25(100.0 \%)$ & $2(8.0 \%)$ & \multirow{2}{*}{$42.593 *$} & \multirow{2}{*}{0.000} \\
\hline & Turbid & $0(0.0 \%)$ & $23(92.0 \%)$ & & \\
\hline \multirow{2}{*}{ TLC } & Mean \pm SD & $265.60 \pm 68.68$ & $1101.60 \pm 536.87$ & \multirow{2}{*}{-7.723} & \multirow{2}{*}{0.000} \\
\hline & Range & $120-400$ & $300-2000$ & & \\
\hline \multirow{2}{*}{ PMN s } & Mean \pm SD & $120.52 \pm 60.71$ & $675.20 \pm 420.02$ & \multirow{2}{*}{-6.535} & \multirow{2}{*}{0.000} \\
\hline & Range & $13-200$ & $150-1900$ & & \\
\hline \multirow{2}{*}{ Lymphocytes } & Mean \pm SD & $144.28 \pm 87.74$ & $426.40 \pm 265.80$ & \multirow{2}{*}{-5.040} & \multirow{2}{*}{0.000} \\
\hline & Range & $60-370$ & $40-1150$ & & \\
\hline \multirow{2}{*}{ Total Protein } & Mean \pm SD & $1.89 \pm 0.21$ & $0.89 \pm 0.33$ & \multirow{2}{*}{12.739} & \multirow{2}{*}{0.000} \\
\hline & Range & $1.5-2.4$ & $0.4-1.8$ & & \\
\hline \multirow{2}{*}{ Glucose } & Mean \pm SD & $119.44 \pm 13.68$ & $134.68 \pm 53.71$ & \multirow{2}{*}{-1.375} & \multirow{2}{*}{0.176} \\
\hline & Range & $89-148$ & $88-352$ & & \\
\hline \multirow{2}{*}{ LDH } & Mean \pm SD & $161.16 \pm 15.17$ & $211.80 \pm 54.52$ & \multirow{2}{*}{-4.474} & \multirow{2}{*}{0.000} \\
\hline & Range & $130-188$ & $134-392$ & & \\
\hline \multirow{3}{*}{$\begin{array}{l}\text { Bacterial } \\
\text { Culture }\end{array}$} & No & $25(100.0 \%)$ & $15(60.0 \%)$ & \multirow{3}{*}{12.500} & \multirow{3}{*}{0.002} \\
\hline & E coli & $0(0.0 \%)$ & $4(16.0 \%)$ & & \\
\hline & Klebsiella & $0(0.0 \%)$ & $6(24.0 \%)$ & & \\
\hline \multirow{2}{*}{ Fungal Culture } & Candida albicans & $0(0.0 \%)$ & $2(8.0 \%)$ & \multirow{2}{*}{$2.083^{*}$} & \multirow{2}{*}{0.149} \\
\hline & No & $25(100.0 \%)$ & $23(92.0 \%)$ & & \\
\hline
\end{tabular}

*:Chi-square test

This table shows:

- There was highly statistically significant difference between 2 groups regarding ascitic fluid aspect, total leucocytic count, PMNs, lymphocytes, LDH and total protein in ascitic fluid.

- There was highly statistically significant difference between 2 groups regarding bacterial culture of ascitic fluid. 
Table (5): The correlation between candidal infection and laboratory results

\begin{tabular}{|c|c|c|c|c|c|}
\hline \multirow{2}{*}{\multicolumn{2}{|c|}{$\mathbf{L A B s}$}} & \multirow{2}{*}{$\begin{array}{c}\begin{array}{c}\text { Negative fungal } \\
\text { culture }\end{array} \\
\text { No.=23 } \\
\end{array}$} & \multirow{2}{*}{$\begin{array}{c}\text { Candida albicans } \\
\text { No. }=2 \\
\end{array}$} & \multicolumn{2}{|c|}{$\begin{array}{l}\text { Independent } t- \\
\text { test }\end{array}$} \\
\hline & & & & $\mathbf{t} / \mathbf{Z}^{*}$ & P-value \\
\hline \multirow{2}{*}{$\mathrm{ALT}$} & Median (IQR) & $33(26-75)$ & $33(28-37)$ & \multirow{2}{*}{$-0.301 *$} & \multirow{2}{*}{0.763} \\
\hline & Range & $7.00-210.00$ & $28.00-37.00$ & & \\
\hline \multirow{2}{*}{ AST } & Median(IQR) & $55(42-96)$ & $82(80-83)$ & \multirow{2}{*}{$-0.902 *$} & \multirow{2}{*}{0.367} \\
\hline & Range & $8.00-280.00$ & $80.00-83.00$ & & \\
\hline \multirow{2}{*}{ Total bilirubin } & Median(IQR) & $2(2-3)$ & $9(2-16)$ & \multirow{2}{*}{$-1.409 *$} & \multirow{2}{*}{0.159} \\
\hline & Range & $1.00-8.00$ & $2.00-16.00$ & & \\
\hline \multirow{2}{*}{ Direct bilirubin } & Median(IQR) & $1(1-2)$ & $5(1-9)$ & \multirow{2}{*}{$-1.157 *$} & \multirow{2}{*}{0.247} \\
\hline & Range & $0.00-5.00$ & $1.00-9.00$ & & \\
\hline \multirow{2}{*}{ Total protein } & Mean \pm SD & $5.84 \pm 0.40$ & $5.50 \pm 0.00$ & \multirow{2}{*}{1.192} & \multirow{2}{*}{0.246} \\
\hline & Range & $5.00-6.00$ & $6.00-6.00$ & & \\
\hline \multirow{2}{*}{ Albumin } & Mean \pm SD & $2.32 \pm 0.38$ & $2.50 \pm 0.00$ & \multirow{2}{*}{-0.667} & \multirow{2}{*}{0.511} \\
\hline & Range & $1.80-3.00$ & $2.50-2.50$ & & \\
\hline \multirow{2}{*}{ UREA } & Mean \pm SD & $71.22 \pm 28.64$ & $105.00 \pm 22.63$ & \multirow{2}{*}{-1.613} & \multirow{2}{*}{0.120} \\
\hline & Range & $30.00-133.00$ & $89.00-121.00$ & & \\
\hline \multirow{2}{*}{ Creatinine } & Mean \pm SD & $1.87 \pm 0.91$ & $2.90 \pm 2.55$ & & 0103 \\
\hline & Range & $1.10-4.60$ & $1.10-4.70$ & -1.341 & 0.193 \\
\hline Sodium $(\mathrm{Na})$ & Mean \pm SD & $126.30 \pm 3.91$ & $124.00 \pm 5.66$ & 0781 & 0443 \\
\hline sodum (Na) & Range & $120.00-138.00$ & $120.00-128.00$ & 0.181 & 0.443 \\
\hline Potacsium $(K)$ & Mean \pm SD & $4.55 \pm 1.00$ & $4.80 \pm 0.71$ & & 0738 \\
\hline Potassium (K) & Range & $3.10-7.50$ & $4.30-5.30$ & -0.539 & 0.138 \\
\hline Total & Median (IQR) & $6600(4900-9600)$ & $8850(620-11500)$ & & \\
\hline $\begin{array}{l}\text { Leucocytic } \\
\text { count }\end{array}$ & Range & $3400.00-18500.00$ & $6200.00-11500.00$ & $-0.701 *$ & 0.483 \\
\hline & Mean \pm SD & $8.45 \pm 0.64$ & $9.45 \pm 1.73$ & & 0430 \\
\hline & Range & $8.00-9.00$ & $6.00-14.00$ & 0.803 & 0.450 \\
\hline & Mean \pm SD & $108500.00 \pm 24748.74$ & $94869.57 \pm 59536.32$ & & \\
\hline Platerets & Range & $91000.00-126000.00$ & $41000.00-337000.00$ & -0.310 & 0.155 \\
\hline & Mean \pm SD & $2.00 \pm 0.71$ & $1.52 \pm 0.30$ & & 0059 \\
\hline INR & Range & $1.50-2.50$ & $1.00-2.30$ & 190 & 0.059 \\
\hline $\mathrm{PC}$ & Mean \pm SD & $38.50 \pm 9.19$ & $50.70 \pm 17.78$ & & 0354 \\
\hline $\mathrm{PC}$ & Range & $32.00-45.00$ & $24.00-100.00$ & 0.940 & 0.354 \\
\hline Prothrombin & Mean \pm SD & $18.50 \pm 2.12$ & $17.95 \pm 3.23$ & & \\
\hline & Range & $17.00-20.00$ & $13.00-27.00$ & 254 & $0.81 /$ \\
\hline & Median (IQR) & $72(36-106)$ & $47(37-56)$ & & 0452 \\
\hline ESK & Range & $37.00-56.00$ & $7.00-136.00$ & & 0.452 \\
\hline CD & Mean \pm SD & $76.50 \pm 30.41$ & $76.87 \pm 36.46$ & & \\
\hline CKP & Range & $55.00-98.00$ & $24.00-158.00$ & & 0.989 \\
\hline $\mathrm{HCV} \mathrm{AB}$ & Yes & $23(100.0 \%)$ & $2(100.0 \%)$ & NA & $\mathrm{NA}$ \\
\hline $\mathrm{HB} \mathrm{sAg}$ & No & $23(100.0 \%)$ & $2(100.0 \%)$ & $\mathrm{NA}$ & $\mathrm{NA}$ \\
\hline
\end{tabular}

*:Mann Whiteny test

This table shows Non-statistically significant correlation between the fungal infection and laboratory investigation. 
Table (6): Comparison between non SP and SP group regarding CHILD and MELD score

\begin{tabular}{|c|c|c|c|c|c|}
\hline & \multirow{2}{*}{$\begin{array}{c}\text { Non SBP } \\
\text { No. }=25\end{array}$} & \multirow{2}{*}{$\begin{array}{c}\text { SBP } \\
\text { No. }=25 \\
\end{array}$} & \multicolumn{2}{|c|}{ Chi-square test } \\
\hline & & & & $\mathbf{X}^{2} / \mathbf{t}^{*}$ & P-value \\
\hline \multirow{2}{*}{ CHILD } & $\mathrm{B}$ & $10(40.0 \%)$ & $10(40.0 \%)$ & \multirow{2}{*}{0.000} & \multirow{2}{*}{1.000} \\
\hline & $\mathrm{C}$ & $15(60.0 \%)$ & $15(60.0 \%)$ & & \\
\hline \multirow{2}{*}{ MELD } & Mean \pm SD & $20.80 \pm 5.40$ & $23.08 \pm 3.85$ & \multirow{2}{*}{$-1.719 *$} & \multirow{2}{*}{0.092} \\
\hline & Range & $12-31$ & $17-36$ & & \\
\hline
\end{tabular}

This table shows Non-statistically significant difference between the two studied groups regarding CHILD and MELD score

\section{Report of the first case of spontaneous fungal peritonitis:}

A 52-year-old female was admitted to the hospital complaining of progressive weakness, increased abdominal distension, abdominal pain, nausea, vomiting, diarrhea and difficult breath. The patient was hospitalized 1 month prior to this admission for hepatic encephalopathy. During that hospitalization, she received anti-coma measures. Her past medical history was significant for end-stage liver disease secondary to hepatitis $\mathrm{C}$ induced cirrhosis. Her HIV status was known to be negative and she had no past history of corticosteroid or immunosuppressive therapy. She had a past history of recent antibiotic use, ceftriaxone, and previous attack of SBP with no prophylaxis for it. Also, she had a past history of refractory ascites and regular tapping. On physical examination, the patient was icteric and febrile $\left(39^{\circ} \mathrm{C}\right)$ with normal other vital signs. Further examination demonstrated scleral icterus, lower limb edema and flapping tremors. Abdominal examination revealed tense ascites with splenomegaly but no signs of guarding or rebound tenderness.

The laboratory data at the time of initial evaluation were as follows: total leukocyte count $11,500 / \mathrm{ml}^{3}$ with $75 \%$ neutrophils; haemoglobin 8 $\mathrm{g} / \mathrm{dl}$; platelets count $126,500 / \mathrm{ml}^{3}$; prothrombin time 20 seconds; ESR (1 st hour) 99 mm; CRP; serum ALT $137 \mathrm{U} / \mathrm{L}$; serum AST $183 \mathrm{U} / \mathrm{L}$ alkaline phosphatase $119 \mathrm{U} / \mathrm{L}$; total bilirubin $15.5 \mathrm{mg} / \mathrm{dL}$; direct bilirubin 8.9; albumin $1.9 \mathrm{~g} / \mathrm{dL}$; fasting blood sugar $90 \mathrm{mg} / \mathrm{dL}$ and creatinine $3.2 \mathrm{mg} / \mathrm{dL}$; serum sodium $116 \mathrm{mEq} / \mathrm{L}$. Hepatitis $\mathrm{C}$ antibody was positive and hepatitis B surface antigen was negative.

Diagnostic and therapeutic abdominal paracentesis were done. Ascitic fluid was turbid and yellow. Ascitic fluid analysis revealed leukocytic count of 900 cells $/ \mathrm{ml}^{3}$ and polymorphonuclear neutrophil count of 350 cells $/ \mathrm{ml}^{3}$; total protein was 2.6 $\mathrm{g} / \mathrm{dL}$; LDH was $251 \mathrm{u} / \mathrm{l}$ and glucose was 131 $\mathrm{mg} / \mathrm{dL}$. She was diagnosed as spontaneous bacterial peritonitis and she was started cefotaxime $2 \mathrm{gm} / 12$ hours till the culture results appeared. Ascitic fluid bacterial culture was negative. Seven days later, the patients ascitic fluid fungal culture grew Candida albicans.

Abdominal ultrasound revealed shrunken cirrhotic liver with dilated portal vein, splenomegaly, normal kidneys and massive ascites. Chest radiograph showed mild right pleural effusion.

The patient was switched to fluconazole $6 \mathrm{mg} / \mathrm{kg}$ intravenously after culture results were obtained. Unluckily, on the 8th day, she died following a massive attack of hematemesis.

\section{Report of the second case of spontaneous fungal peritonitis:}

A 76-years-old male was admitted to the hospital complaining of progressive weakness, increased abdominal distension, abdominal pain, nausea, hematemesis, melena, and difficult breath. The patient was hospitalized 2 months prior to this admission for hepatic encephalopathy. During that hospitalization, he received anti-coma measures. His past medical history was significant for end-stage liver disease secondary to hepatitis $\mathrm{C}$ induced cirrhosis. His HIV status was known to be negative and he had no past history of corticosteroid or immunosuppressive therapy. He had a past history of recent antibiotic use; ceftriaxone, and no previous attacks of SBP with no prophylaxis for it. Also, he had a past history of refractory ascites, regular tapping, DM, hypertension and renal impairment. On physical examination, the patient was febrile $\left(39^{\circ} \mathrm{C}\right)$ with normal other vital signs. Further examination demonstrated lower limb edema and flapping tremors. Abdominal examination revealed moderate ascites with splenomegaly but no signs of guarding or rebound tenderness.

The laboratory data at the time of initial evaluation were as follows: total leukocyte count $6200 \mathrm{cell} / \mathrm{ml}^{3}$ with $75 \%$ neutrophils; hemoglobin 
$8.9 \mathrm{~g} / \mathrm{dl}$; platelets count $91,000 / \mathrm{ml}^{3}$; prothrombin time 17 seconds; ESR (1st hour) 102; CRP; serum ALT $28 \mathrm{U} / \mathrm{L}$; serum AST $80 \mathrm{U} / \mathrm{L}$ alkaline phosphatase $107 \mathrm{U} / \mathrm{L}$; total bilirubin $2.2 \mathrm{mg} / \mathrm{dL}$; direct bilirubin 1.1 ; albumin $2.5 \mathrm{~g} / \mathrm{dL}$; fasting blood sugar $167 \mathrm{mg} / \mathrm{dL}$ and creatinine $4.7 \mathrm{mg} / \mathrm{dL}$; serum sodium $128 \mathrm{mEq} / \mathrm{L}$. Hepatitis C antibody was positive and hepatitis $\mathrm{B}$ surface antigen was negative.

Diagnostic and therapeutic abdominal paracentesis were done. Ascitic fluid was turbid and yellow. Ascitic fluid analysis revealed leukocytic count of 1500 cells $/ \mathrm{ml}^{3}$; polymorphonuclear neutrophil count of 900 cells $/ \mathrm{ml}^{3}$ and lymphocytes 600 cells $/ \mathrm{ml}^{3}$; total protein was $2.7 \mathrm{~g} / \mathrm{dL}$; LDH was $210 \mathrm{u} / \mathrm{l}$ and glucose was $167 \mathrm{mg} / \mathrm{dL}$. He was diagnosed as spontaneous bacterial peritonitis and he was started cefotaxime $2 \mathrm{gm} / 12$ hours till the culture results appeared. Ascitic fluid bacterial culture was negative. Five days later, the patients ascitic fluid fungal culture grew Candida albicans.

Abdominal ultrasound revealed cirrhotic liver, splenomegaly, grade I nephropathy and moderate ascites. Chest radiograph showed mild right pleural effusion. The patient was switched to fluconazole $6 \mathrm{mg} / \mathrm{kg}$ intravenously after culture results were obtained. Unluckily, on the 6th day, he died after cardio-pulmonary arrest.

\section{DISCUSSION}

The relationship between immune dysfunction and infection in cirrhosis, known as cirrhosis-associated immune dysfunction syndrome (CAIDS), has been investigated extensively. This syndrome is a multifactorial state of dysimmunoregulation, which is comprised of a reduction in serum bactericidal activity, opsonic activity, and complement and fibronectin levels [5].

Spontaneous peritonitis is a common condition. It is usually seen in patients with end-stage liver disease and ascites. The most common underlying cause for spontaneous peritonitis is bacterial infection; however, very rarely fungal infections can be the causative agents [6].

Infective peritonitis is categorized into primary, secondary, or tertiary according to pathologic etiology. Primary peritonitis also known as spontaneous (bacterial) peritonitis, typically occurs in the setting of ascites without an obvious source of infection. In this condition, it is theorized that organisms seed the peritoneum through a complex process involving intestinal bacterial overgrowth, translocation of bacteria across the bowel wall, and impaired host defenses. Secondary peritonitis results from a breach in the integrity of the gastrointestinal or genitourinary tract and may involve bacterial or fungal organisms. Tertiary peritonitis occurs after treatment of secondary peritonitis has failed, and signs and symptoms of peritonitis persist [7].

Fungal infection is usually overlooked, with a delay in diagnosis, or passes without being noticed. This low index of suspicion might be due to a lack of signs of infection such as fever, or to the absence of the classic picture of peritonitis. Sometimes, clinical presentations of spontaneous fungal peritonitis are largely indistinguishable from those of spontaneous bacterial peritonitis. Further factors contributing to fungal cultures not being performed routinely are the long period required for fungal growth and suboptimal microscopic evaluations and culture [8].

This study was conducted on 50 patients with decompensated chronic liver disease, admitted to Al-Shabrawishi hospital. Their ages ranged from 36 to 76 years with a mean age of $60.96 \pm 9.08$. Twenty-nine $(58 \%)$ of them were males and twenty-one $(42 \%)$ were females.

These patients were classified into two groups:

- Group I: Included 25 patients with cirrhotic ascites had spontaneous peritonitis (SP group).

- Group II: Included 25 patients with cirrhotic ascites had no spontaneous peritonitis (non SP group).

Spontaneous peritonitis is diagnosed when PMN count in ascitic fluid $>250 / \mathrm{ml}^{3}$ in the absence of data compatible with secondary peritonitis [9].

The present study revealed that, SP was more in males (56\%) than females (44\%) and it was not influenced by age. This result was in agreement with the study done in Saudi Arabian patients with non-alcoholic liver cirrhosis and they stated that SBP was frequent in males and was not affected by the age [10].

Analysis of the results showed that abdominal pain, hepatic encephalopathy and melena were the only significant clinical presentations (chief complaint) in patients with SP compared to non SP group (52\%, 40\% and $8 \%$ respectively). These results are not in cop with a study which stated that melena was $60 \%$ from clinical presentation [11], this may be due to the wide 
spread prophylactic band ligation of esophageal varices nowadays.

Fever was detected in $76 \%$ of SP group and this was highly statistically significant as a symptom suggestive of SP. One study reported that, fever was detected in $66 \%$ of SBP cases [12], which was different to the result of the present study.

Abdominal pain was detected in $52 \%$ of SP group. This was lower than the results elicited by a study which stated that, abdominal pain was detected in $75 \%$ of SP cases [11]. This difference could be explained by a study which summarized that, the clinical picture of SP is extremely broad and very variable and a very high degree of clinical suspicion is required for diagnosis [13].

Diarrhea was detected in $12 \%$ of SP group and $36 \%$ of non SP group and this was statistically significant. The low frequency of diarrhea is due to the fact that most hepatic patients suffer from constipation rather than diarrhea.

Regarding liver function tests, the total plasma proteins were significantly lower in SP than non SP patients. ESR, first-hour values, was significantly higher in SP group than non SP group. CRP values also were significantly higher in SP group than non SP group with a median (IQR): 76. Otherwise, no statistically significant differences were recorded in the other parameters of the liver profile, prothrombin time and kidney functions.

One study found no significant difference in liver biochemistry, which is similar to the result of the present study [11]. Ascitic fluid WBCs, PMN count, lymphocytes were significantly higher in SP group than non SP group. One study stated that, although ascitic total WBC count increases in SBP cases, it suffers from low specificity because a large proportion of patients with sterile ascites have increased white blood cell counts. Also diuretic therapy has been shown to increase the total white blood cell count but does not alter the PMN count [14].

LDH was significantly higher in SP group than non SP group especially those associated with malignancy with Mean \pm SD: $211.80 \pm 54.52$. Total proteins in ascitic fluid were significantly lower in SP group.

Ascitic fluid bacterial culture was positive in 10 cases $(40 \%)$ of SP group and negative in all cases of non SP group and was highly significant. The isolated organisms in SP group were E. coli in 4 cases (16\%), Klebsiella in 6 cases $(24 \%)$.

One study detected positive ascitic fluid bacterial culture in $41.7 \%$ of cases of SP which was close to the result of the present study [15]. In SP group, the isolated organisms were monomicrobial, gram negative aerobic pathogens. This was in agreement with a study which stated that, single gram negative organisms (especially E. coli and Klebsiella) cause most episodes of SBP [12].

Culture negative neutrocytic ascites (CNNA) which is considered as a variant of SBP was detected in $55 \%$ of SP cases in this study. Culture negativity may be due to low concentration of bacteria in ascitic fluid. This was in agreement with a study which stated that, in spite of using good culture techniques; cultures are still negative in approximately $30-50 \%$ of patients with an increased ascites PMN count [16].

Ascitic fluid fungal culture was positive in only two cases of SP group and negative in all cases of non SP group. The isolated organism was Candida albicans. The ascitic fluid bacterial culture of the two cases of spontaneous fungal peritonitis was negative (culture negative neutrocytic ascites).

History of therapeutic abdominal paracentesis was detected in $40 \%$ of patients of SP group with statistical significant difference when compared to the non SP group in which $12 \%$ of patients had a similar history. In agreement with our study another study reported that, therapeutic paracentesis does not increase the early or the long term risk of development of SBP in cirrhotic patients with ascites [17]. One study stated that, needle induced ascitic fluid infection do not occur unless the bowel is penetrated by the paracentesis needle, that occurs in only one in 1000 taps [18].

As regard gastrointestinal bleeding, it was found that, 20\% of SP patients had an attack hematemsis and melena before the episode of SP with no significant difference from non SP group (24\%).

Our results are in agreement with the study which stated that spontaneous fungal peritonitis associated with cirrhosis to be a rare process, as evidenced by the small number of cases reported in the literature, this low frequency of fungal infection in cirrhotic patients may be due to the lack of prolonged neutropenia and the presence of adequate numbers of functional neutrophils required for normal fungal host defense in the circulation [19]. 
We found no significant differences between patients with and without fungal infection as regards the clinical judgment, which is in agreement with one study [8].

In this study, increased ascitic fluid lymphocytes were seen among patients with fungal infections. This is in agreement with one study [20] which added that lymphocytes predominance may be a clue to non-bacterial causes, with consideration of a possible spontaneous fungal peritonitis.

Also, we showed that the two cases of spontaneous fungal peritonitis had a clinical picture of spontaneous bacterial peritonitis but with neutrocytic negative bacterial culture ascites, supporting that this variant of spontaneous bacterial peritonitis is also a feature of fungal peritonitis.

We found no significant correlation between the fungal infection of ascitic fluid and laboratory investigation, ascitic fluid parameters, MELD score and prophylactic antibiotics. This was in contrast with a study which reported that the use of prophylactic antibiotics, low ascitic fluid protein $(<1 \mathrm{~g} / \mathrm{dl})$, a higher MELD score were found to be independently associated with fungal infections [9]. Moreover, patients with multiple risk factors were more predisposed to such infections. It has been postulated that these prophylactic antibiotics suppress or change the normal intestinal flora leading to fungal overgrowth; these organisms then migrate across the intestinal wall to reach the peritoneal cavity and cause fungal peritonitis and dissemination. This may be explained by the few number of SFP cases.

The 3-months survival rate was lower in the SP group especially SFP cases than NON SP group $(44 \%, 88 \%)$ respectively. This is in agreement with the study which showed a higher mortality rate in cirrhotic patients who developed spontaneous fungal peritonitis [21].

Advanced hepatic cirrhosis, disseminated fungal infection, and delayed diagnosis may contribute to these high mortality rates. Thus, there should be an increased awareness of fungal infection in patients with advanced cirrhosis, as delayed diagnosis and treatment may lead to serious consequences [9]. The small number of patients in this series is one of the limitations of our study. Further studies with larger populations are needed on fungal infections, with special attention given to high-risk patients with ESLD.

\section{Funding: None}

\section{Conflicts of interest: None}

Ethical approval: The protocol of the study was approved by the ethical committee of Faculty of Medicine, Benha University. Informed consents were obtained from all patients.

\section{REFERENCES}

1- Wiest R; Krag A, Gerbes A. Spontaneous bacterial peritonitis: recent guidelines and beyond. Gut 2012; 61: 297-310.

2- Runyon, B.A. Introduction to the revised American Association for the Study of Liver Diseases Practice Guideline management of adult patients with ascites due to cirrhosis 2012. Hepatology 2013; 57(4): 1651-1653.

3-Theresa Bucsics; Philipp Schwabl; Mattias Mandorfer; Markus Peck-Radosavlievic . Prognosis of cirrhotic patients with fungiascites and spontaneous fungal peritonitis (SFP). Journal of Hepatology 2016; 64 (6): 1452-1454.

4- Arnold C, Haag K, Blum H.E , Rossle M. Acute haemoperitoneum after large- volume paracentesis. Gastroenterology 1997; 113: 978 - 982.

5- Bonnel AR, Bunchorntavakul C , Reddy KR. Immune dysfunction and infections in patients with cirrhosis. Clin Gastroenterol Hepatol 2011; 9:72738 .

6- Cleophas V, George V, Mathew M, Samal SC, Chandy GM. Spontaneous fungal peritonitis in patients with hepatitis B virus related liver disease. J Clin Gastroenterol; 2000; 31(1):77-79.

7- Such, J. , Runyon, B.A. Spontaneous bacterial peritonitis. Clin. Infect. Dis 1998; 27 (4): 669-674.

8- Saif MW, Raj M. Cryptococcal peritonitis complicating hepatic failure: case: report and review of the literature. J Appl Res 2006; 6:43-50.

9- Hwang SY, Yu SJ, Lee JH, Kim JS, Yoon JW, Kim YJ et al. Spontaneous fungal peritonitis: a severe complication in patients with advanced liver cirrhosis. Eur J Clin Microbiol Infect Dis 2014; 33: 259-264.

10- Ageely, H.; Ayoola, E.A.; Al-Hazim, M. , Gadour M. Spontaneous bacterial peritonitis in Saudi Arabian patients with non -alcoholic liver cirrhosis. Hepatogastroenterology, Dec 2000; 47 (36): $1649-53$.

11- Nouh A,Elhendy A,Eldeeb G,Ellehleh A, Salah A. Spontaneous fungal peritonitis: Occurrence in patients with cirrhotic ascites. Menofia Medical Journal 2008; 21:2: 5-16. 
12- Llovet, J.; Planas, R.; Morillas, R, Quer JC, Cabre E, Boix J,et al. Short term prognosis of cirrhotics with spontaneous bacterial peritonitis: multivariate study. Am. J. Gastroenterology 1993; 88 (3): 388-392.

13- Rimola, A. and Navasa, M: Infection in liver disease. In: Oxford textbook of clinical hepatology. Bircher J, Benhamou J, McIntyre N, Rizzetto M, Rodes J, editors. New York: Oxford University Press 1999. 1861 - 76.

14- Jansen, P. Spontaneous bacterial peritonitis. Detection, treatment and prophylaxis in patients with liver cirrhosis. Neth. J. Med 1997; 51(4): $123-128$.

15- Llovet, J.; Moitinho, E.; Sala, M, Bataller R, Rodriguez-Iglesias P, Castells A., et al. Prevalence and prognostic value of hepato cellular carcinoma in cirrhotic patients presenting with spontaneous bacterial peritonitis. J. Hepatology 2000; 33: 42329.

16- Navasa M, Follo A, Filella X, Jimenez W, Francitorra A, Planas R, et al. Tumor necrosis factor and interleukin -6 in spontaneous bacterial peritonitis in cirrhosis: relationship with the development of renal impairment and mortality. Hepatology; 1998; 27 (5): 1227 - 1232.
17- Sola M, Andreu M, Coll S, Carme-Villa M, Oliver M , Arroyo V. Spontaneous bacterial peritonitis in cirrhotic patients treated using paracentesis or diuretics: Results of a randomized study. Hepatology 1995; 21 (2): 340 - 344.

18- Runyon, B.A. Paracentesis of ascitic fluid: a safe procedure. Arch. Intern. Med 1986; 146(11): $2259-2261$.

19- Hassan EA, Abd El-Rehim AS, Hassany SM, Ahmed AO, Elsherbiny NM, Mohammed MH. Fungal infection in patients with end-stage liver disease: low frequency or low index of suspicion. Int J Infect Dis 2014; 23: 69-74.

20- Choi SH, Soo Kim Y, Chung JW, Choo EJ, Kwak YG, Lee YS et al. Clinical significance of untreated Candida species isolated from ascites in cirrhotic patients. Scand J Infect Dis; 2004. 36(9):649-655.

21- Stiefel P, Pamies E, Miranda ML, Martin-Sanz MV, Fernandez-Moyano A, Villar $\mathrm{J}$ et al. Cryptococcal peritonitis: report of a case and review of the literature. Hepatogastroenterology; 1999; 46: 1618-1622. 